\title{
Removal of Heavy Metals Using Low Cost Adsorbents
}

\author{
Dr. Jai M Paul ${ }^{1}$, Jis Jimmy ${ }^{2}$, Josento M Therattil ${ }^{2}$, Linda Regi ${ }^{2}$, Shirin Shahana ${ }^{2}$ \\ ${ }^{1}$ Asst. Professor in Civil Engineering Department, M.A. College of Engineering Kothamangalam, Kerala \\ ${ }^{2}$ Btech students in Civil Engineering Department, M.A. College of Engineering Kothamangalam, Kerala
}

\begin{abstract}
Much attention has been made towards adsorbent materials to be used in heavy metal removal from polluted water and various techniques are applied such as chemical, physical and biological techniques. This study was designed for using less expensive and much frequently available materials (mango peels, Neem leaves $\&$ coconut husk) to remove iron, copper and cadmium from water. Current data show that all adsorbents used are capable of removing copper, iron and cadmium ions at significant capacity. Furthermore, coconut husk had higher capability than mango peel and neem leaves.
\end{abstract}

Keywords: Heavy metals, Adsorption, Removal Efficiency, Contact time, Particle size

\section{Introduction}

Water pollution due to development in technology, continues to be of great concern. With increasing generation of heavy metals from technological activities, many aquatic environments face metal concentrations that exceed water quality criteria designed to protect the environment, animals and humans. Heavy metals are chemical elements with a specific gravity that is at least 5 times the specific gravity of water and is toxic or poisonous even at low concentrations. Some well-known toxic metallic elements with their specific gravity are arsenic, (5.7); iron.(7.9); chromium.(7.19); cadmium,(8.65); lead,(11.34); and mercury,(13.54). Heavy metals are highly dispersed in a wide variety of economically important minerals. They are released to the environment during mineral extraction process. Therefore, mining activities are considered as the primary anthropogenic source of heavy metals. Heavy metal ions are discharged into water system from various industrial activities such as electroplating industries, electronic equipment manufacturing, and chemical processing plants. Due to rapid development of industrial activities, the levels of heavy metals in water systems have substantially increased. Heavy metals can easily enter the food chain because of their high solubility in water. Cadmium, copper, chromium, lead and zinc are extremely toxic heavy metals of widespread use in many industries. The heavy metals pollution represents an important problem, with human health concerns and serious ecological consequences. It is therefore essential to remove heavy metals from industrial waste waters and drinking water. Plant materials are mainly comprised of cellulose materials that can adsorb heavy metal cations in aqueous solution. Numerous waste biomass sources are available in nature in which adsorption properties have been reported e.g rice husk, saw dust, tea and coffee waste, orange peel peanut shells, activated carbon, dry tree leaves and barks. Adsorption of heavy metal ions occur as a result of physicochemical interaction, mainly ion exchange or complex formation between metal ions and the functional groups present on the cell surface.

\subsection{Preparation of adsorbent.}

\section{Materials And Methods}

The experiments are to be carried out using the adsorbent mango peel, neem leaves and coconut husk. The adsorbent samples were collected from the near by locality and washed several times with distilled water to remove dust and other impurities. Then drying, it was ground using domestic mixer and sieved to 250 mesh size. The samples were washed with distilled water to remove colour and dried in an oven at $80{ }^{\circ} \mathrm{C}$ for 24 hours. The dried sample was stored in airtight bottles for further use without any chemical or physical treatment.

\subsection{Preparation of aqueous solution of metals}

All reagents used in this study are of analytical grade obtained from Merck Germany. Stock solutions of iron, Cadmium, Copper was prepared by metal nitrate salts in double distilled water and the required concentrations were obtained by diluting the stock solutions. Test methods cover the determination of metal ions in water samples prepared in accordance with ASTM methods.

\subsection{Batch adsorption studies}

Adsorption experiments were carried out by adding various amount of adsorbents $(1 \mathrm{gm} / \mathrm{L}, 2 \mathrm{gm} / \mathrm{L}$, $3 \mathrm{gm} / \mathrm{L}, 4 \mathrm{gm} / \mathrm{L}, 5 \mathrm{gm} / \mathrm{L}$ ) dried adsorbent into $500 \mathrm{ml}$ metal solutions. Samples were stirred continuously. After 2 hour till 8 hours the samples were taken and filtered and analyzed using Atomic Adsorption Spectrophotometer. 


\subsection{Concentration of adsorbents}

\section{Results And Discussions}

The concentration of adsorbents was varied between $1 \mathrm{~g} / \mathrm{L}$ to $5 \mathrm{~g} / \mathrm{L}$ keeping all other parameters constant. From the graphs it was found that the adsorption rate of iron, cadmium \& copper using mango peels, coconut husk \& neem leaves increases with the increase in concentration of adsorbents. The maximum removal of iron using mango peel, coconut husk \& neem leaves were $66.46 \%, 80.22 \% \& 72.08 \%$ respectively. The maximum removal of cadmium using mango peel, coconut husk \& neem leaves were $84.18 \%, 88.77 \%$ \& $73.33 \%$ respectively. The maximum removal of copper using mango peel, coconut husk \& neem leaves were $73.19 \%, 84.28 \%$ \& $59.18 \%$ respectively The optimum value of adsorbent dose for the removal of heavy metals(iron, cadmium, copper) using the above natural adsorbents was found to be $5 \mathrm{~g} / \mathrm{L}$.

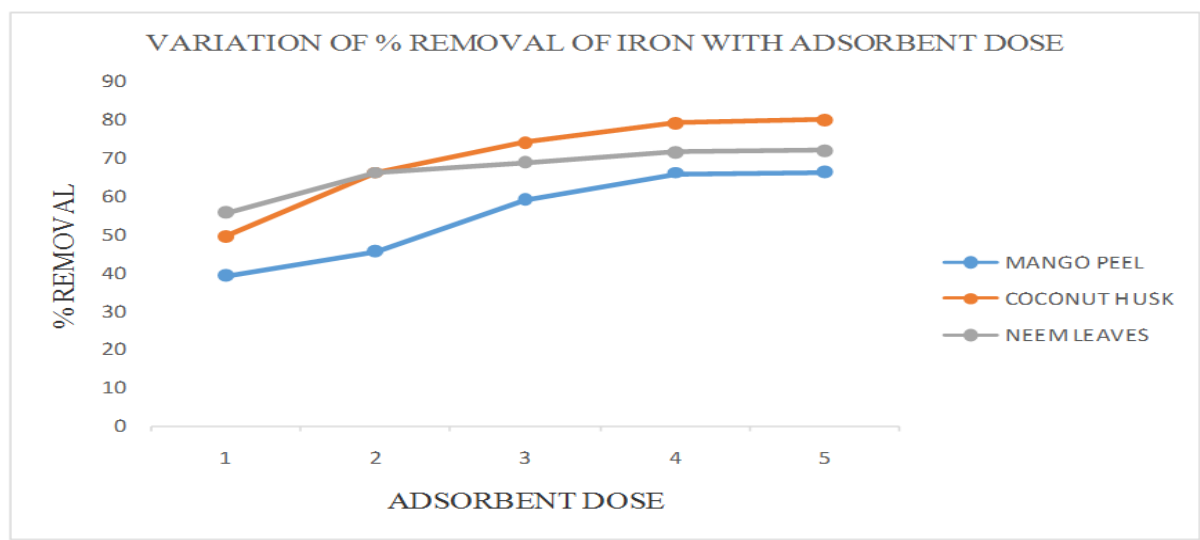

Figure 1. Variation of \% removal of Iron with adsorbent dose

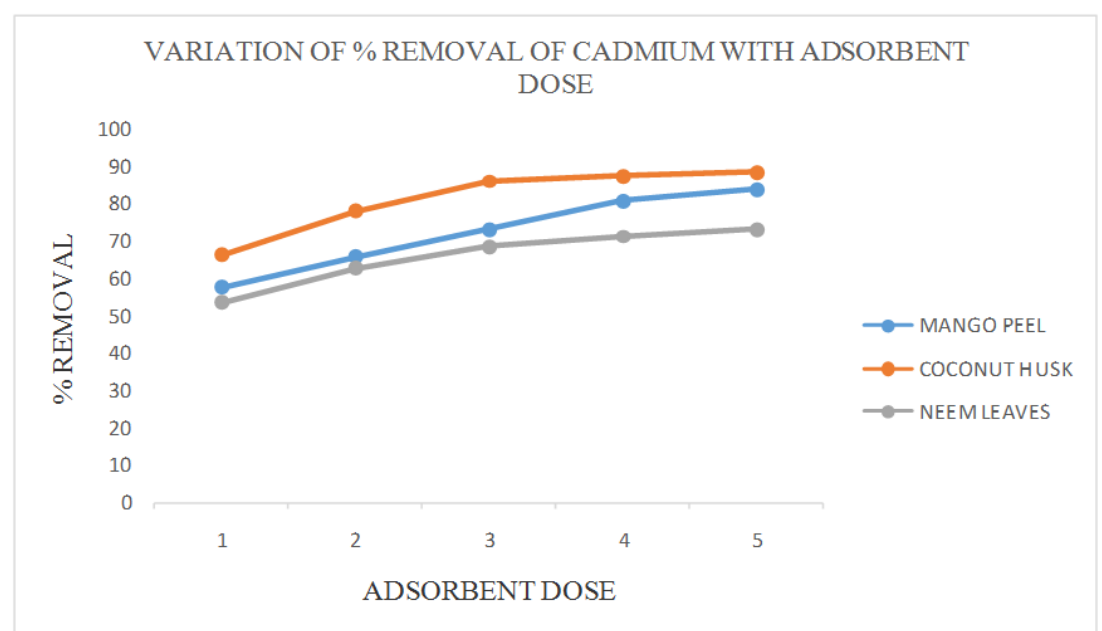

Figure 2. Variation of \% removal of Cadmium with adsorbent dose

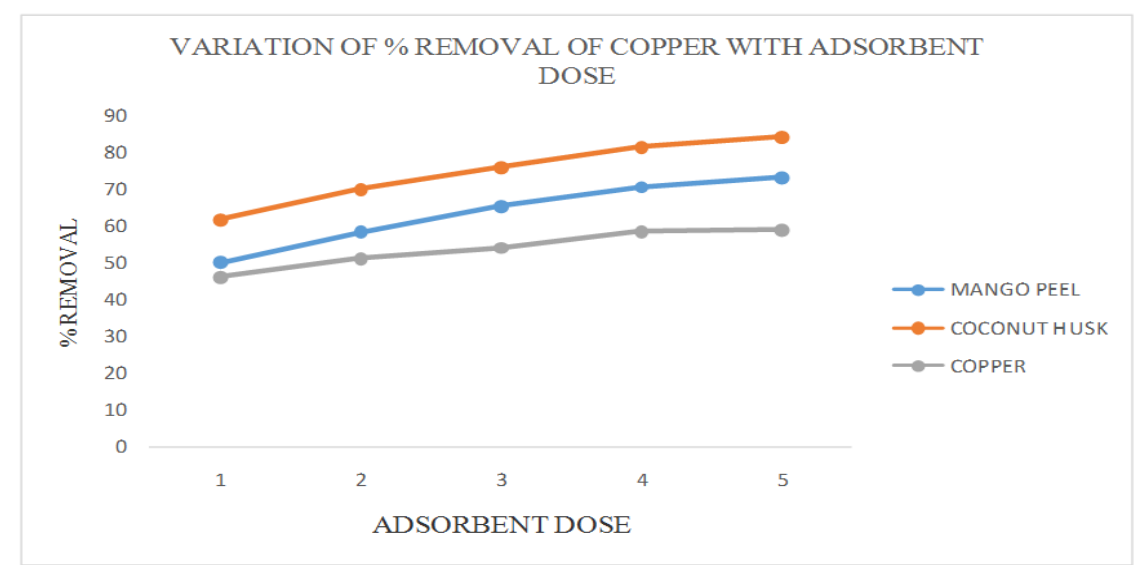

Figure 3. Variation of \% removal of Copper with adsorbent dose 


\subsection{Contact Time}

For adsorption the contact time was varied from 2 to $8 \mathrm{hrs}$ for the maximum removal of metals. The maximum removal of metals (iron, cadmium \& copper) using mango peels, neem leaves $\&$ coconut husk was obtained after 8 hours of contact time. After 8 hours there was no significant adsorption of the metals.

\subsection{Particle size}

Adsorption studies were carried out using different particle sizes in the range of 150 to 600 microns. The optimum particle size of mango peel for the removal of heavy metals(iron, cadmium \& copper) was between 400-500 microns. The optimum particle size of coconut husk for the removal of heavy metals(iron, cadmium \& copper) was between 150-200 microns. The optimum particle size of neem leaves for the removal of heavy metals (iron, cadmium \& copper) was between 100-200 microns.

\section{CONCLUSION}

Studies on cadmium, iron and copper removal using mango peels, neem leaves $\&$ coconut husk showed significant effects of the variables adsorbent dose, contact time, particle size of adsorbent materials etc. The results provide a good indication of the different operating conditions that would be required for efficient removal of each heavy metal from aqueous solution. Bio-sorption increases with increase in amount of adsorbent and contact time but become almost constant after certain dose of adsorbent and time. It was found that the adsorption rate of heavy metals using natural adsorbents increases initially with increase in the particle size of adsorbent but decreases after a certain value This study can be applied for the removal of iron, copper, cadmium from the water and this study is fairly helpful in developing a wastewater treatment plant for the removal of copper, iron, cadmium from the waste water by using the cheap materials which will be economical and easy to carry out.

\section{References}

[1]. R Balaji,S Sasikala,G Muthuraman.Removal of Iron from drinking or ground water by using agricultural waste as natural adsorbents, International Journal of Engineering and Innovative Technology,volume 3, issue 12,June 2014

[2]. [2] Madhukar J. Phadtare,Removal of heavy metal from industrial waste water,International Journal of Advanced Engineering Research and Studies,E-ISSN2249-8974

[3]. [3] Chetan S. Mahajan, Dhananjay B. Sarode, Ramanand N. Jadhav, Sanjay B. Attarde, Sopan T. Ingle,Removal of heavy metal from waste water by using natural adsorbents,International journal of conservation science Volume 5, Issue 1, January-March 2014: 69-78.

[4]. [4] Samiksha V. Ashtikar,Adsorption of Copper from Aqueous Solution Using Mango Seed Powder Journal of Engineering Research and Applications ISSN : 2248-9622, Vol. 4, Issue 4( Version 7), April 2014, pp.75-77.

[5]. [5] Dr. Jai M. Paul, Amal M Vijayan, Anargha Raju, Megha C.S, Sadique K. (2016), "Comparison of Iron Removal Effeciency by Areation and Adsorption" (IOSR-JMCE) e-ISSN: 2278-1684,p-ISSN: 2320-334X, Volume 13, Issue 3 Ver. II (May - June 2016), PP 01-4. 